\title{
Solution to NMR hide-and-seek challenge
}

\author{
Reinhard Meusinger ${ }^{1}$
}

Published online: 20 March 2017

(C) Springer-Verlag Berlin Heidelberg 2017

The winner of the NMR hide-and-seek challenge (published in volume 408 issue 27) is:

John Warren, LGC, Teddington, UK.

The award entitles the winner to select a Springer book of his choice up to a value of $€ 100$.

Our congratulations!

\section{Solution}

The substance described in the NMR hide-and-seek challenge [1] is histamine (Fig. 1).

In the realm of natural products, histamine is one of the simplest nitrogen-containing compounds. The colourless hygroscopic crystals melt at $83.5^{\circ} \mathrm{C}$ and are easily dissolved in water. In aqueous solution histamine exists in two tautomeric forms (Fig. 2).

Histamine plays an important role in the human body: it is involved in several physiological functions as in immune responses and it acts as a neurotransmitter. The compound was synthesized first by Windaus and Vogt in 1907 via Curtius degradation of imidazole propionic acid hydrazide. They noted: "we have not yet fully investigated this peculiar substance. The investigation progresses slowly because of the diffi-

This article is the solution to the Analytical Challenge to be found at http://dx.doi.org/10.1007/s00216-016-9860-x

Reinhard Meusinger

meusi@nmr.chemie.tu-darmstadt.de

Institute of Organic Chemistry and Biochemistry, University of Technology Darmstadt, Alarich-Weiss-Str. 4,

64287 Darmstadt, Germany cult accessibility of the starting material. Nevertheless we report the previous results now, since others are working on the synthesis of histidine as well" [2]. Three years later Dale and Laidlaw [3] fully described many of the physiological effects of this substance.The name "histamine" was derived from "histo" and "amine", yielding "tissue amine". Occasionally in the medical literature the term " $\mathrm{H}$ substance" is used for histamine or a hypothetical histaminelike diffusible substance released in allergic reactions of skin and in the responses of tissue to inflammation. However, the histamine content of a single nettle hair was found to be only $6 \mathrm{ng}$ [4].

For structural determination the ${ }^{1} \mathrm{H}-{ }^{13} \mathrm{C}$ heteronuclear multiple bond correlation spectrum is given with the complete assignment of all carbon and hydrogen atoms that are detectable in dimethyl- $d_{6}$ sulfoxide solution of histamine dihydrochloride (Fig. 3).<smiles>NCCc1c[nH]cn1</smiles>

Fig. 1 Histamine $\left(\mathrm{C}_{5} \mathrm{H}_{9} \mathrm{~N}_{3}, M=111.15 \mathrm{~g} / \mathrm{mol}\right)$. IUPAC name 2-( $1 \mathrm{H}$ imidazol-4-yl)ethanamine<smiles>NCCc1cnc[nH]1</smiles>

$\mathrm{H}$

Fig. 2 The tautomeric forms of histamine 
Fig. 3 Heteronuclear multiple bond correlation spectrum of histamine [500 MHz, dimethyl- $d_{6}$ sulfoxide $(D M S O)]$. The symmetrical satellite signals are residual single quantum coherence signals (so-called heteronuclear single quantum coherence artefacts) and are marked by $X$

\section{References}

1. Meusinger R. Anal Bioanal Chem. 2016;408:7537-41.

2. Windaus A, Vogt W. Ber Dtsch Chem Ges. 1907;40:3691-5.
3. Dale HH, Laidlaw PP. J Physiol. 1910;41:318-44.

4. Oliver F, Amon EU, Breathnach A, Francis DM, Sarathchandra P, Black AK, et al. Clin Exp Dermatol. 1991;16:1-7. 